\title{
Analysis of Constructive Effect That Amplification and Omission Have on the Power Differentials - Taking Eileen Chang's Chinese-English Self-translated Novels as Examples
}

\author{
$\mathrm{Hao} \mathrm{He}$ \\ Gan Su Normal University for Nationalities, Hezuo, Gansu, 747000, China \\ Xiaoli Liu \\ Gan Su Normal University for Nationalities, Hezuo, Gansu, 747000, China
}

\begin{abstract}
By taking Eileen Chang's two Chinese-English self-translated novels as examples, this paper analyzes the construction effect that employment of amplification and omission has on the asymmetrical power relationships from four aspects of critical discourse analysis: classification system, transitivity system, modality system and transformation system. The conclusion is that the author-translator's adoption of amplification and omission serves for the construction of asymmetrical power relationships, which has negative influence on cultural communication based upon equality between the west and the east.
\end{abstract}

Index Terms-Eileen Chang, Chinese-English self-translation, amplification and omission, critical discourse analysis

Eileen Chang was a legendary writer in Chinese literature history in 20th century but few people know that she is also an excellent translator. She has translated many English novels including Hemingway's The Old man and The Sea and some of her own works. In recent years, the research on Eileen Chang is very hot whereas the research on her translation, especially on her self-translation is limited. It is easy for us to take for granted that it should be the most faithful that the author translates his/her own works. Actually it is strange that while translating her own novels, Eileen Chang always employed two translation techniques, amplification and omission. Translation is a process of conflict, collision and violence between one culture and another in the aspect of ideology, cultural traditions. It's reflects powers. At the same time translation participates in the construction of power. Translation has become an accomplice to sustain the asymmetrical power relationships among various cultures. In this paper, taking Eileen Chang's two Chinese-English self-translated novels Shame Amah! and Naked Earth as examples, the effect that the employment of amplification and omission has on the asymmetrical power relationships will be analyzed according to four dimensions of critical discourse analysis which stresses the invisible embodiment of power and ideology in text.

\section{Classification System}

Classification is a process or a result in which objects are categorized into different kinds according to their attributes and characters (Sun Zhixiang, 2009, p.78). By virtue of classification system, people can recognize an object and its relations to other objects so as to know the whole world. Language is also a system in which classification is of great significance. When people try to express themselves, they actually classify the world using the words and this kind of classification is controlled by people's linguistic background and their ways to understand which are usually agreed by the whole society. Foucault said that knowledge is power. Here, we could say language is power which penetrates in every aspects of our life. In other words, people classify according to the so-called commonsense. As Fairclough has once pointed out that common sense reflects ideology of a society more or less and helps to maintain the asymmetrical power relations (Sun Zhixiang, 2009, p.83). The classification based on common sense is hence a field in which different groups of people either struggle to keep their classification system or yield to accept classification system of people who have more power. When it comes to translation, cases that dominant culture imposes their classification system on dominated culture are by no means rare and on the other hand it is common that dominant culture disdains and tampers the classification system of dominated culture. During translating process, translators always choose different systems of classification considering such factors as ideology differences and reader acceptance. It is the difference between classification systems in original and target texts that reflects the power differentials. How does classification help to maintain asymmetrical power relations? Next, we will analyze some typical strategies.

A. Overlexicalization

Overlexicalization refers to a way of description by using a great deal of synonyms. Overlexicalization always 
demonstrates the experience or value that the language users concern, which helps readers to understand the ideological orientation of the writers (Sun Zhixiang, 2009, p.86). In translation, translators often tend to put synonyms next to each other so that readers are attracted and the meaning that he/she wants to covey is easy to be understood and intensified. In translation of Naked Earth, employment of amplification reflects ideological strategy of overlexicalization.

Example 1:

“你听听, 你听听! ”李向前对冯天佑说: “人家都说出来了, 只有你一个人护着他, 甘心做他的狗腿子。” (Eileen Chang, 2000, p.14)

"You hear? You hear?" Pao said to Feng. "They are talking. You're the only one who still defends him, content to be his kou t'ui-tze, dog's leg." (Eileen Chang, 1956, p.25)

Here the translation of foul language is very thought-provoking. Firstly, Eileen Chang adopted Chinese pinyin to imitate the pronunciation of the word and then explained the meaning of the word through free translation. Furthermore, the word was italicized, which accentuated the foul language. Readers would naturally pay more attention to the word. On one hand, the amplification was used to stress the foul language, which helped to depict an image of ugly Chinese man who was so rude and weird. For western readers, such a people was a real Other, a barbarian, which met their impression on Chinese people. On the other, this was a sentence used by Li Xiangqian, a cadre of Communist Party, to persuade Feng Tian You, a poor peasant to expose the evil behavior of a rich peasant. The amplification of the foul language uglified the image of Communist member and was effective to arouse disgust and anger among western people. Such kinds of examples are not rare. For instance, “阎王债” was translated as "nieng-wong chai, a loan from the king of hell” and “大力干他们” was translated into “ta li kang t'ameng, do them in with great force” etc. All these words intensify the stereotyped image of the eastern people in western people's mind. In a word, the ideological strategy of overlexicalization reflected through amplification serves for the asymmetrical power relationships between China and the western countries and the asymmetrical power relationships are strengthened accordingly.

\section{B. Biased Naming}

It is a disputable problem whether a name has special meaning. Russel holds that every name has significant meaning which is the signified of the word whereas in Kripke's opinion, name has no meaning, the relation between the names and the signified is established at the moment the name is given (Sun Zhixiang, 2009, p.90). Actually, process of naming has some conventional elements which demonstrate that naming is a social activity and names do have meaning. In literary creation, writers always pay great attention to naming of the character and a name always infers a people's identity, characteristic or even his/her destiny. For example, in ancient Chinese novel A Dream of Red Mansion, every character's name has significant meaning. As to the translation of names, transliteration is a widely adopted way. While translating names, Eileen Chang employed different methods. In Shame Amah!, she renamed all the characters and in Naked Earth, transliteration and other techniques are used.

Example 2:

支部书记李向前是一个瘦子, 穿着一件高领子的白布小补, 一双很精灵的大眼睛, 眼泡微微凸出来。(Eileen Chang, 2000, p.3)

The secretary of the Party branch office, Pao Hsiung-ch'ien, Go Forward Pao- a name obviously adopted after the Liberation-was a youngish farmer with thin, birdlike good looks, rather high-shouldered in a high-collared white Chinese shirt. (Eileen Chang, 1956, p.5)

"Xiang Qian" has been a very common name in China since liberation, which expressed the optimistic attitude that Chinese people held towards new China and socialism construction. In English version, the author-translator first adopted transliteration to imitate the pronunciation but the family name "Li" was changed in to "Pao", then English paraphrasing of the word was added. As stated previous, the name in novel can always reflect a person's image or his/her nature. Go Forward Pao is a name which gives readers impression that the man owning the name is a very funny person. Combining with the description of appearance following the name, readers would assume that Li Xiangqian was a funny, deceitful man which is the "classic image" of Chinese people in western people's mind and naturally arouses repugnance among readers. The author-translator used a name with strong ideological color to display image of a Communist member and amplified it through adding explanation. This process of biased naming has close relation to asymmetrical power relationships, while giving name to a person, the translator is naturally in favor of a side of asymmetrical power relationships, as a result, the asymmetrical power relationships was constructed without being noticed.

The employment of amplification and omission, on one hand, intensifies the Orientalist stereotyped image of the east in western readers' mind, which may cause more discrimination form the west. On the other hand, it gets more difficult for the east to get rid of the stereotype. As a result, the communication between the east and the west becomes harder to achieve.

\section{TRANSITIVITY SYSTEM}

Text has value of representation, experience and relationship, among which experience value is embodied in transitivity and voice of the sentence. The function of transitivity system is to dissect the things that people see, feel or do into process types and then to demonstrate participants and environmental elements of different process through categorizing human's experience by virtue of grammar(Sun Zhixiang, 2009, p.103). In critical discourse analysis, the value of the text is regarded as order of discourse which always reflects certain power relationships, so the micro 
process of choice of words always has relation to construction of power relationships. As to translation, choice of transitivity system is controlled by cognition of translator. While translating, translators firstly study the choice of transitivity and its ideological features in original text to analyze and reveal the power relationships reflected in transitivity system. Meanwhile choice of transitivity is also a way for translators to participate social construction.

\section{A. Implicitation or Explicitation of Participant}

In Chinese language, it is common that a sentence has no subject whereas in English a subject is indispensible. It is assumed that a Chinese sentence without subject could be translated into English in passive voice. Translators either use object as subject or just add the subject, in other words, add the participants. But how to add the participants demonstrates the translator's attitude towards power relationships and translators always adopt certain strategies to intensify or weaken the asymmetrical power relationships.

Example 3:

这一向看看乡下情形不对，风声一天紧似一天，他半个月前就想溜，预备留下老婆孩子，一个人逃出去投靠 他丈人。(Eileen Chang, 2000, p.13)

He had been scared by the talk of Land Reform and had made an attempt to escape to Peking, leaving his wife and children behind. (Eileen Chang, 1956, p.22)

"He" referred to a coward person who was said to be a landlord and actually hadn't much money. In original text, the reason why he wanted to escape was obscurely mentioned. But in English version, the author-translator added the participant, it was Land Reform that made him want to escape even not caring his family. Here the explicitation of Land Reform intensifies its negative side, which serves for ideology and asymmetrical power relationships between the west and the east. Combining the given background information, the western readers were easy to demonize the Land Reform. Hence the misunderstanding that western people have on Land reform, on Chinese revolution and even on China was getting deeper and deeper.

Similarly, the translator will also adopt method of dissimulation to cover or dilute the negative side of dominant party in power relationships.

Example 4:

他走出来接电话，先咳嗽一声，可是喉咙还有些浑浊。他问道: “哈罗? ”, 然后, 突然声音变得极其微弱: “哈罗哦! ” 又惊又喜, 销魂地, 等于说: “是你么? 难道真的是你么? ”他是一大早起来也能够魂飞魄散为情 颠倒的。(Eileen Chang, 2003, p.153)

He cleared his morning throat before he picked up the phone. "Hello?" Then his voice grew faint, "Hello-O!" as though overcome.(Eileen Chang, 1962, p.95)

The word "overcome" is usually used as a transitive verb and when used in passive voice it means to be extremely affected by something. But here it was used as if it were a intransitive verb. Both subject and object were omitted. Readers may be puzzled: he was overcome by what? The voice? The ironic effect brought by the eight words “魂飞魄 散为情颠倒” has totally disappeared.

\section{B. Shift in Information Focus}

The structure of information distribution was controlled by ideology. In positive or neutral context, the dominant party of power relationships is in subject position, on the contrary, in negative context, the dominated party of power relationships is in subject position (Sun Zhixiang, 2009, p.126).

Example 5:

刘荃在北大的时候, 是学生会里的一个活动分子, 和其他几个大学里的学生组织经常有接触。他口才虽然不 见得好, 人很诚实可靠, 又是青年团的团员。张励显然很倚重他..... (Eileen Chang, 2000, p.2)

Liu had been active in the Students' Association of Peita, the University of Peking, so he had been in constant contact with similar groups in all the other universities. He was also a member of the Youth Corps and was being considered for admittance into the Party. Chang obviously regarded him as a leader among the students... (Eileen Chang, 1956, p.3)

Comparing the Chinese and English version we could see that in Chinese version Liu Ch'uen was prominent among students because he was active, honest and a member of Youth Corp whereas in English version his prominence had nothing to do with his honest and another reason was added. It was that he "was being considered for admittance into the Party." The passive voice was eye-catching in the whole sentence, which gave readers the impression that admittance into the Party had little relationship to his own willingness, he was just dominated. It was his being dominance that the so-called freedom publicized by the west was hinted. Combining with Liu's betrayal of the Party at the end of the novel, the author-translator successfully fulfilled the task of the novel: to uglify the Communist Party.

\section{MODALiTy SYSTEM}

Modality system is very complex. In traditional linguistic study, modality is considered as a part of verbal system and linguists' researches on modality system always concern about usage of modality system in morphology and syntax. Actually, application of modality system is by no means limited as what is described in traditional grammar. Kress\& Hodge (1979) hold that modality is a way demonstrating the truth, reliability and authority of the discourse. Writers express their opinions and influence the attitude and manner of readers through language. They employ modality system to express their degree of affinity towards the topic, so, although it is only an adjunct of a sentence in form, modality is 
a useful way adopted by a writer to emphasize his/her own opinions. Therefore it is meaningful to research the construction of asymmetrical power relationships in translation through analysis of modality system in both original and target text.

Example 6:

只要是个女人, 他 (哥儿达先生) 都要使他们死心塌地喜欢他......哥儿达先生把被单枕套衬衫裤大小毛巾一 起泡在浴缸里, 不然不放心, 怕她不当天统统洗掉它。(Eileen Chang, 2003, p.155)

Mr. Schacht had soaked all his sheets and towels and underwear in the tub to make sure that she would wash it all that day. (Eileen Chang, 1962, p.97)

In asymmetrical power relationships, the dominant party always adopts affirmative modal form. The modal verb “要” means let or want to do which discloses the stingy nature of Schacht. But in English version, the sentence was omitted to dissolute the negative side of the dominant party. As for the second sentence, there is no modal verb in original text, but in English version, the modal verb "would" was added and the negative objective clause was changed to affirmative one. One meaning of "would" is "of willingness", and the readers' focuses were transferred from pettiness of Schacht and it seemed that his behavior was reasonable. Obviously, the employment of amplification and omission here is compromise to asymmetrical power relationships between the west and the east.

\section{TRANSFORMATION SYSTEM}

As to "transform", different schools have different definitions and in CDA the study of transformation system is closely related to the study of metaphorical system. Metaphor is a very common phenomenon in human language and the study of metaphor has long history. Aristotle held that metaphor was transfer application of one's name to another thing, that is to say metaphor was transformation between nouns. But it is too simple to define it only at lexical level and it's necessary to study grammatical metaphor which should be carried out in certain context. When it comes to the translation study, it is necessary to research how the writers/translators implement ideological strategies by using metaphor to influence the readers and finally to serve for the asymmetrical power relationships.

\section{A. Lexical Metaphor}

Lexical metaphor used to be regarded as rhetorical method other than ideological strategy. Actually, metaphor has social, political and ideological significance (Sun Zhixiang, 2009, p.160). The amplification and omission of metaphor may possibly facilitate dissimulation or reification of asymmetrical power relationships.

Example 7:

大家实在困倦得很厉害，不久也就鼾声四起了。(Eileen Chang, 2000, p.5)

The loud snoring around him seemed to have die down as if the sleeping men were now far away from him. Their rafts were well over to the other shore of the night while he still had endless darkness ahead of him. (Eileen Chang, 1956, p.8)

Lexical metaphor usually has the same signifier and the different signified. The signifier "endless darkness" has two different meanings, one is the darkness of the night, the other is the darkness of the society that could only be felt by Liu Ch'uen, the representative of the civilized man, and other people, to be exact, Chinese people are too ignorant to feel the darkness. Through the added sentence, the western readers, especially those who have already had prejudices upon China, would certainly accept the dark terrible image of China, of Land Reform, they would have the same feeling with Liu Ch'uen - in such a society, future was dark. During translation, the author-translator endowed Chinese society with nature of darkness that easily gave rise to negative impression upon China among English readers, which served to construct the asymmetrical power relationships between the west and China.

\section{B. Grammatical Metaphor}

Compared with lexical metaphor, grammatical metaphor is much more covert. Halliday once pointed out that grammatical metaphor was what a grammatical structure was substituted by another and noun beame dominant component in construction mode of grammar (Sun Zhixiang, 2009, p.165). That is to say, the typical form of grammatical metaphor is nominalization. Main function of nominalizations is to gloss over the agent's questionable role or manipulate social and cultural focuses of interest and or to foreground as common sense knowledge and opinions (Sun Zhi xiang, 2009, pp.168-170).

Example 8:

有一群人围在车子旁边看着, 指指戳翟。(Eileen Chang, 2000, p.4)

A lot of people had gathered around the truck parked on the wayside...They doubled up, slapping their knees, helpless with laughter, as if they were the funniest-looking objects in the world. Men and women, both wearing old little sleeveless blouses of white cloth, also bent down peering and giggling but barking prohibitive phrases at the children. (Eileen Chang, 1956, p.6)

The author-translator added the description of image of Chinese people in the form of nominalization which helped to manipulate focuses of readers. Process of nominalization always change the local or short movement into permanent nature and therefore those description of Chinese people may root in western readers' mind and whenever they think of Chinese people, these descriptions will come into their mind. It became harder and harder for the eastern people to reveal true self to the western people and to communicate equally with them. 


\section{Summary}

Under various asymmetrical power relationships, the author-translator follow the Orientalism discourse by employing techniques of amplification and omission and meanwhile the process of translation, as Niranjana had once said, "embodies and constructs the asymmetrical power relationships manipulated by colonialism"(Wang Yan, 2008). This paper tried to study Eileen Chang's self-translation in historical context to which she belonged so as to help us understand the influence that the asymmetrical power relationships have on translation and on the other hand, to study translation techniques of amplification and omission from a different perspective. Eileen Chang was a superior female Chinese writer and she was a diasposed writer and translator as well. This paper, from certain degree, revealed that the process she tried to integrate into western world was very difficult. Today, inequality between the west and the east still exists, so what kind of effect it has on today's translators and how can the translators diminish the inequality through translation?

\section{REFERENCES}

[1] Chang, Eileen. (1956). Naked Earth. Hong Kong: Hong Kong Union Press.

[2] Chang, Eileen. (1962). Eight Stories by Chinese Women. In Nieh Hua-ling(Eds.), Shame Amah! (pp.91-114). Taipei: Taipei Heritage Press.

[3] Chen Jirong. (2009). A study of Translation Theory:Based on Self-translation. Beijing: China Social Science Press.

[4] Fei Xiaoping. (2003). Power and Rebellion: Postcolonial Translation Theory. Study of Comparative Literature in China 4,112-117.

[5] Gao Quanzhi.(2006). Interview of Mr. Macthy. In Chen Zishan(Eds.), Memory about Chang Eileen (pp.224-245). Shandong: Shandong Pictorial Press.

[6] Jin Hongda. (2005). Chang Eileen. Beijing: The Culture and Art Press.

[7] Lv Jun. (2002). From Theory to Discourse:A study of Translation. Journal of Sichuan Foreign Language College 1,23-25.

[8] Robinson, Douglas. (2007). Translation and Empire: Postcolonial Theories Explained. Beijing: Foreign Language Teaching and Research Press.

[9] Said, Edward. (1978). Orientalism. London: Routledge \& Kegan Paul.

[10] Sun Huijun. (2005). Ubiquity and Disparity. Shanhai: Shanghai Translation Press.

[11] Sun Zhixiang. (2009). Critical Analysis of Ideology in Text and Study of translation of the Text. Beijing: China Social Science Press.

[12] Wang Dongfeng. (2003). Postcolonial Translation. China Translation 7, 3-8.

[13] Wang Xiaoying. (2008). A Study of Chang Eileen's Translation: From a Multiple View.China Translation 5, 25-29.

[14] Wang Xiaoying. (2009). Study on Chang Eileen's Chinese- English Self-translation: A Postcolonial Perspective. Foreign Language 4, 125-129.

[15] Wang Yan. (2008). Analysis of Deterioration of Europeanization in Chinese. Scientific and Technological Translation in China $8,40-43$.

[16] Xu Shigu. (2002). Analysis of Cases on Cultural and Language Hegemony. In Zhang Boran \&Xu Jun (Eds.), Translation Study in $21^{\text {st }}$ Century (pp560-564). Beijing: Commercial Press.

[17] Zhang Yanyan. (2008). On YangKo and Naked Earth. Chinese Literature 3, 21-29.

[18] Zhang Hongyan \& Yi Lixin. (2006). Reflection on Power Discourse. Journal of ZhongNan Ethnical University 2, $160-162$.

Hao He was born in Gansu, China in 1975. He is a Tibetan. He received his M.A. degree in ALP Department from California State University, East Bay, USA .in 2011.

He is currently an associate professor in the Foreign Languages Department, Gan Su Normal University for Nationalities, Gansu, China. His research interests include bilingual linguistics and American literature.

Dr. He is a member of the Chinese Association of Foreign Language Teachers.

Xiaoli Liu was born in Gansu, China in 1973. She received her M.A. degree in Literature Department from Lanzhou University, China in 2012.

She is currently a lecturer in the Chinese Department, Gan Su Normal University for Nationalities, Gansu, China. Her research interests include Chinese dialect and Chinese literature.

Mrs. Liu is a member of the committee Chinese language and literature Teachers. 